
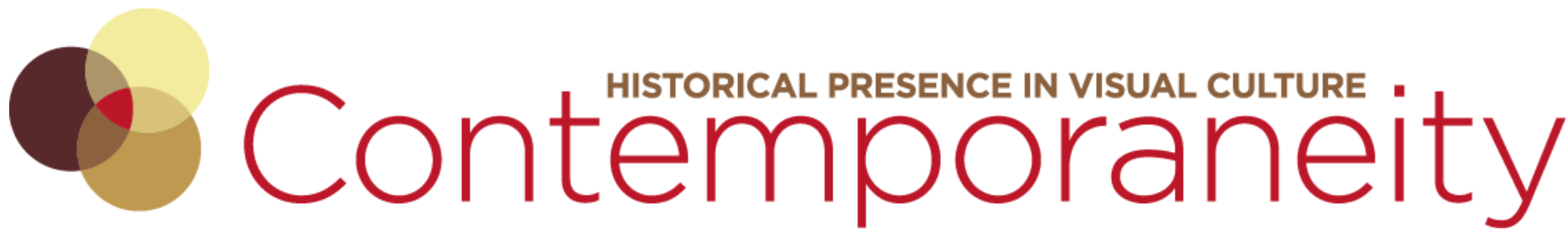

Vol 6, No 1 "Boundless" (2017) | ISSN 2153-5914 (online) | DOI 10.5195/contemp.2017.227

http://contemporaneity.pitt.edu

\title{
Multiple Temporalities, Layered Histories
}

\author{
Steven Pearson
}

\section{About the Artist}

Steven Pearson is a painter and Professor of Studio Art in the Art and Art History Department at McDaniel College in Westminster, Maryland, where he has been teaching studio art courses since 2004. He also serves as the director of the college's Esther Prangley Rice Gallery, an exhibition space for McDaniel students and other emerging contemporary artists from the Mid-Atlantic region and beyond.

Pearson was born in Johnstown, NY. Upon graduation from high school, he served honorably in the United States Navy. Pearson then received his bachelor of science in studio art from the College of Saint Rose in Albany, NY, and his master of fine arts in painting from the Leroy E. Hoffberger School of Painting at the Maryland Institute College of Art in Baltimore, MD. During his training at both the undergraduate and graduate levels, Pearson's work focused primarily on narrative figuration. After graduation, he painted still lifes, investigating the formal and conceptual nature of everyday objects. By appropriating formal compositional devices explored by modern and contemporary artists-such as Kazimir Malevich, Ad Reinhardt, Donald Judd, and Jules Olitski-Pearson constructed still lifes using commonplace objects, including cardboard boxes and paper lunch bags. While Pearson was a resident at the Vermont Studio Center in 2003, his work became increasingly abstract, while remaining committed to exploring the still life genre. During a residency at the Ragdale Foundation in Illinois in 2005, Pearson's work further evolved to become, essentially, nonobjective. Throughout the various shifts in Pearson's painting styles, order and structure provide the connecting thread in his development, echoing his early experiences in the Navy. 


\section{Multiple Temporalities, Layered Histories}

\author{
Steven Pearson
}

In Quotational Practices: Repeating the Future in Contemporary Art, Patrick Greaney asserts, "the past matters not only because of what actually happened but also because of the possibilities that were not realized and that still could be. Quotation evokes those possibilities. By repeating the past, artists and writers may be attempting to repeat that past's unrealized futures. ${ }^{11}$ In the information age, the Internet, for instance, provides us an expanded collection of visual information-quite literally available at our fingertips-summoning together aspects of the past and possibilities of the future into a boundless present. Sketchbook Revisions (2014-2015), a series of mixed-media paintings, represents my attempt to communicate the ways in which I experience my contemporary moment constructed from multiple temporalities excavated from my past. This body of work combines fragments of representational paintings created between 1995 and 2003 and nonrepresentational renderings produced between 2003 and 2014. Using traditional tracing paper and graphic color, I randomly select moments of my previous work to transfer and layer over selected areas of already-filled pages of a sketchbook I used from 2003 to 2004. These sketches depict objects I encountered in studio art classrooms and iconic architecture on the campus of McDaniel College, and often incorporate teaching notes. The final renditions of fragmented and layered histories enact the ways that we collectively experience multiple temporalities in the present. Quoting my various bodies of work, Sketchbook Revisions challenges both material and conceptual boundaries that determine fixed notions of artistic identity.

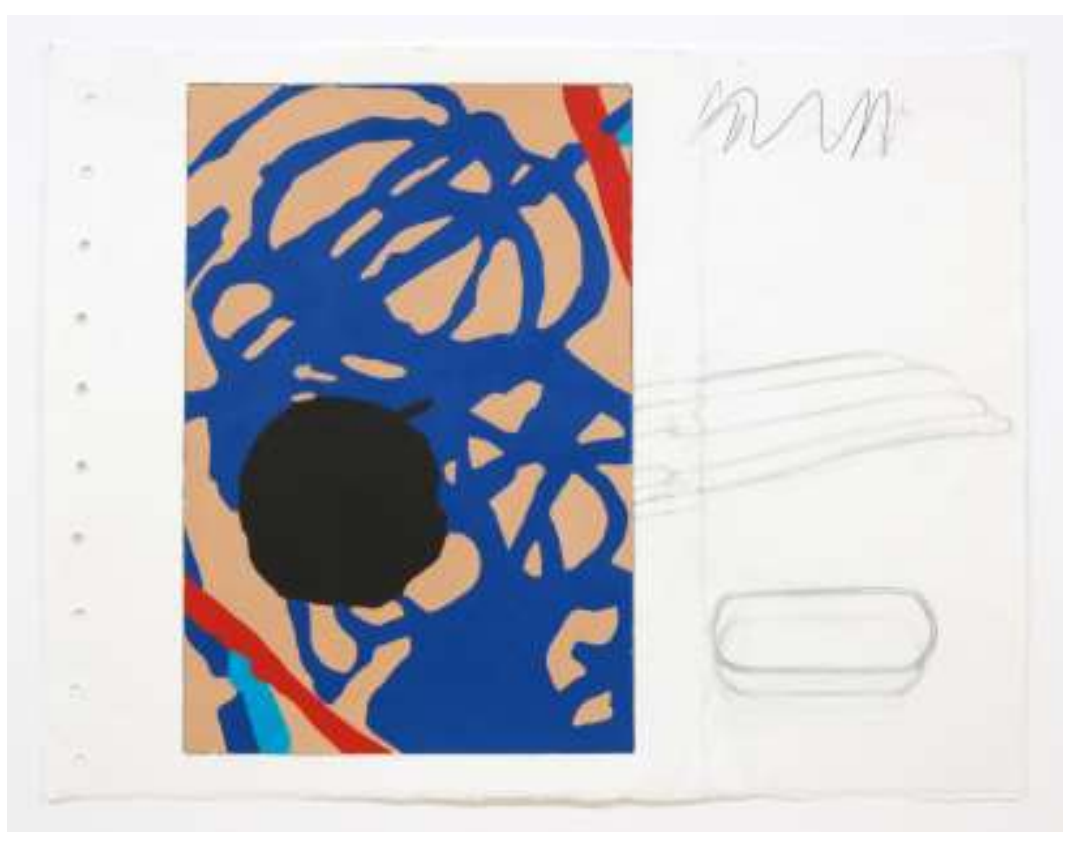

Figure 1

Steven Pearson, Sketchbook Revisions: Woodwing and Scribble, 2014, graphite and acrylic on Rives BFK, $12 \times 9$ in.

1 Patrick Greaney, Quotational Practices: Repeating the Future in Contemporary Art (Minneapolis, MN: University of Minnesota Press, 2014), x. 


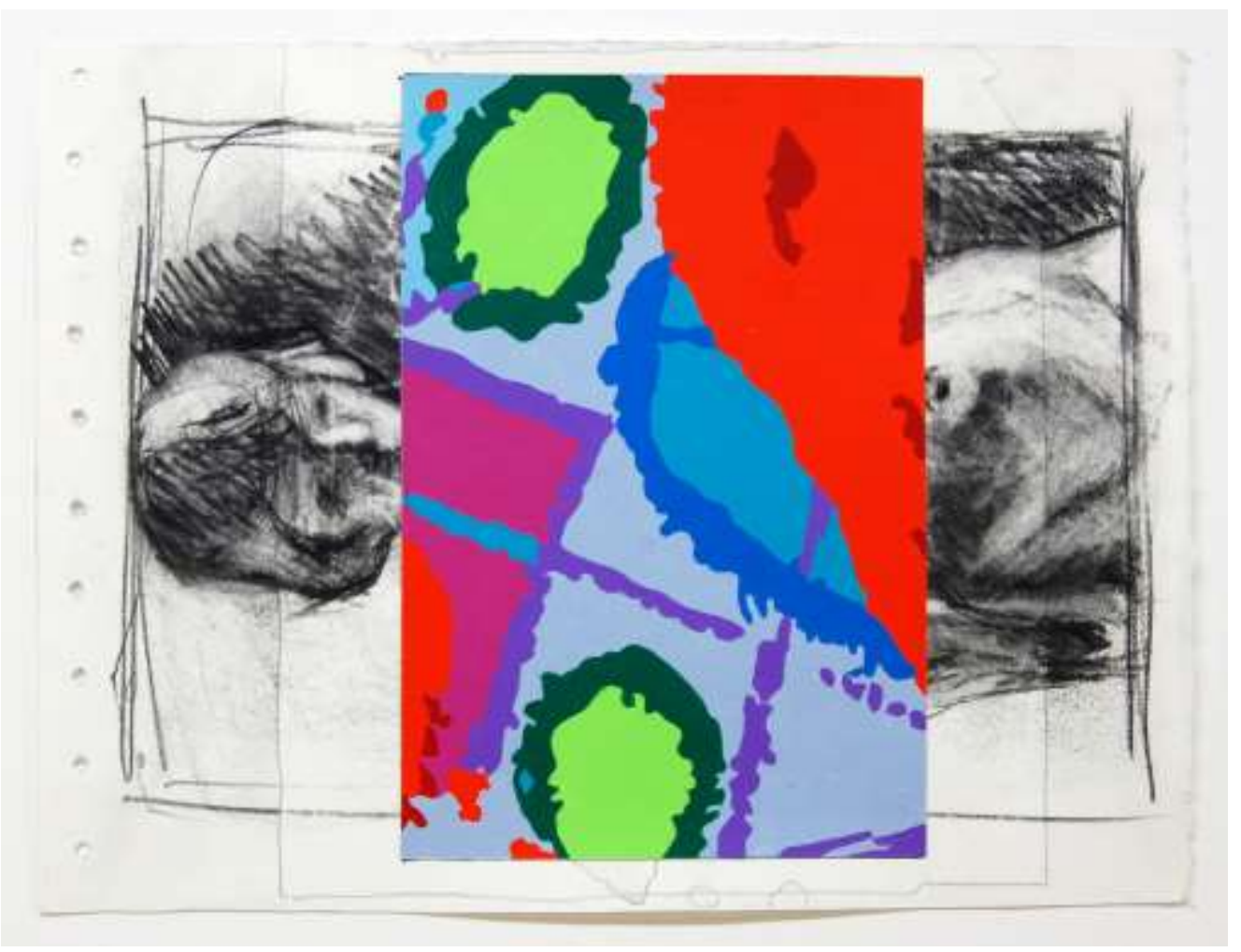

Figure 2

Steven Pearson, Sketchbook Revisions: Plaster Model (Vertical), 2014, charcoal, graphite, and acrylic on Rives BFK, 12 × 9 in. 


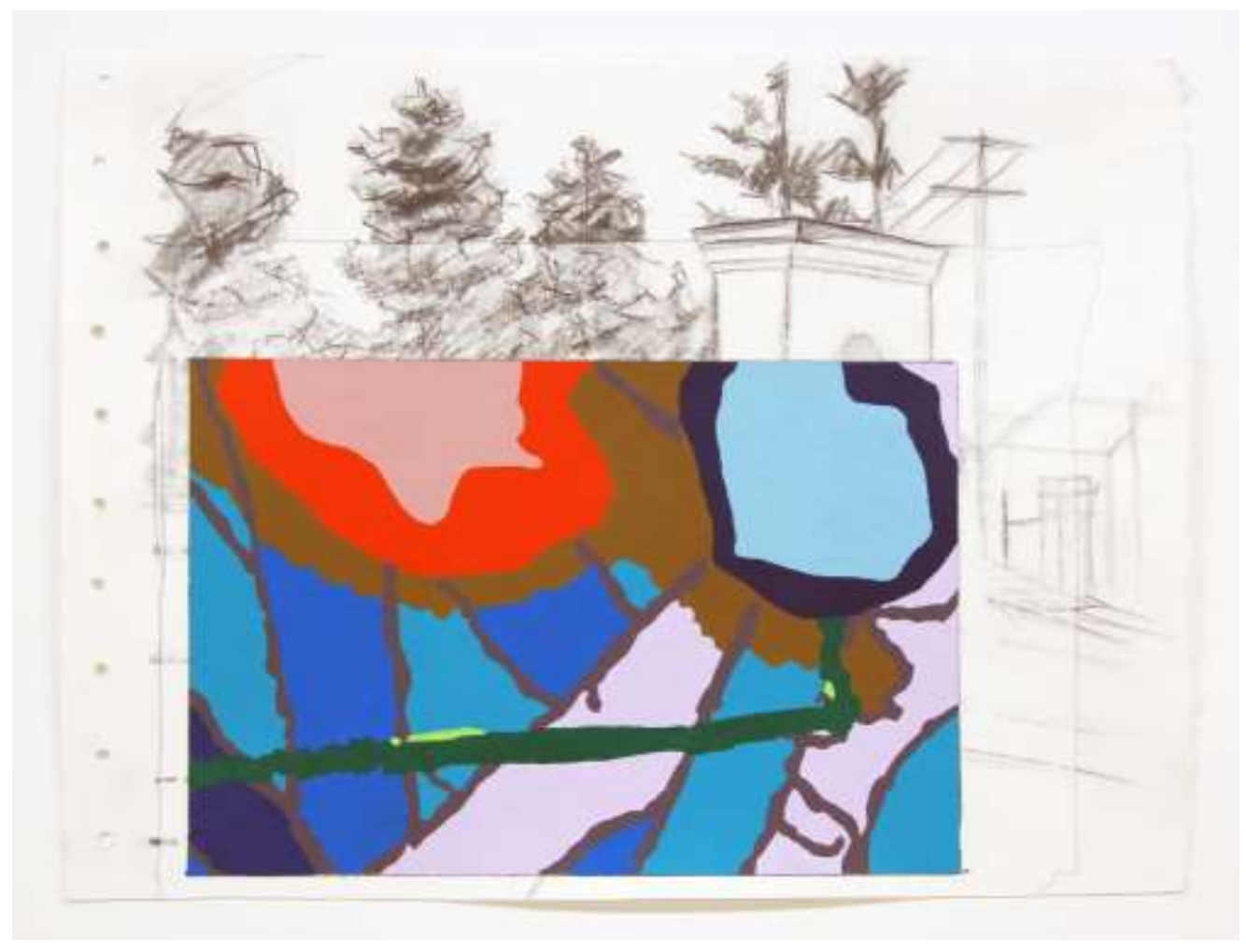

Figure 3

Steven Pearson, Sketchbook Revisions: The Arch, 2014, graphite and acrylic on Rives BFK, 12 × 9 in. 


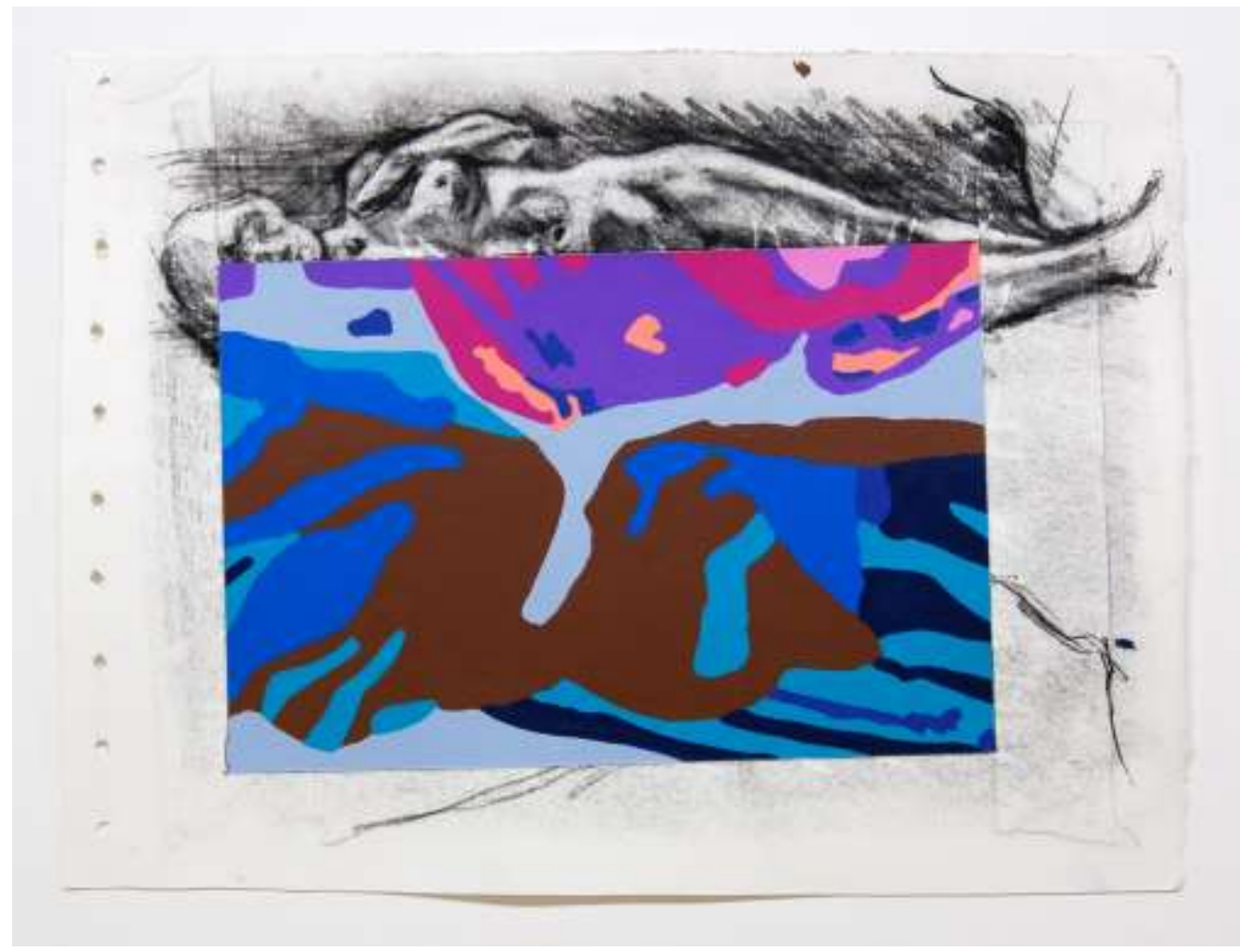

Figure 4

Steven Pearson, Sketchbook Revisions: Plaster Model (Vertical), 2014, charcoal, graphite, and acrylic on Rives BFK, $12 \times 9$ in. 


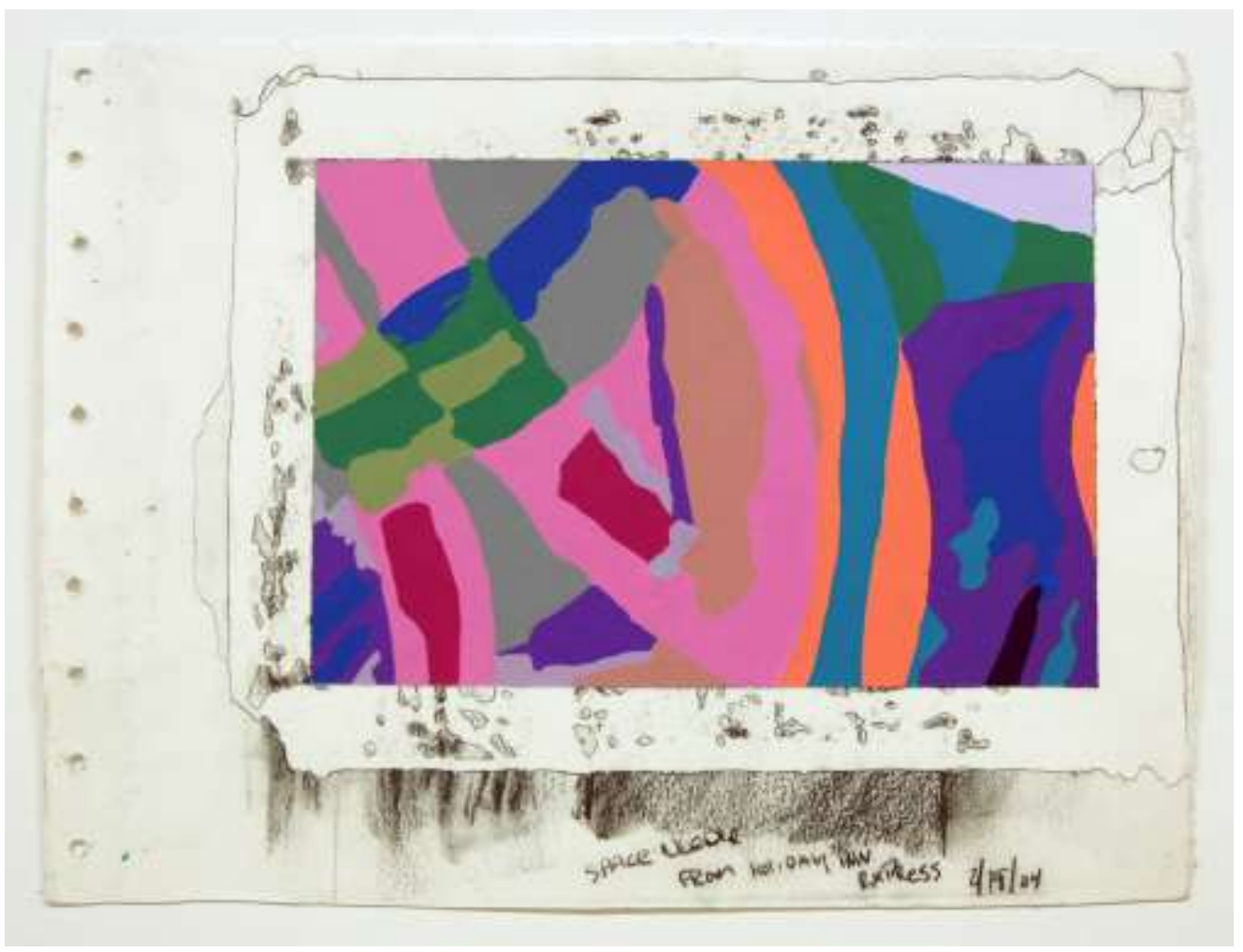

Figure 5

Steven Pearson, Sketchbook Revisions: Space Needle, 2014, charcoal, graphite, and acrylic on Rives BFK, $12 \times 9$ in.

(cc) $\mathrm{BY}$ New articles in this journal are licensed under a Creative Commons Attribution 4.0 United States License.

\section{ULIS D-Sonle}

This journal is operated by the University Library System of the University of Pittsburgh as part of its D-Scribe Digital Publishing Program, and is co-sponsored by the University of Pittsburgh Press. 